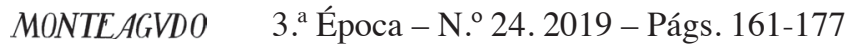

\title{
NUEVAS FORMAS Y SOPORTES DE ESCRITURA POÉTICA EN LATINOAMÉRICA
}

\author{
LAURA LóPEZ FERnÁNDEZ \\ University of Waikato, Hamilton, Nueva Zelanda
}

\section{RESUMEN:}

En este artículo se exploran distintas modalidades de escritura experimental en Latinoamérica, desde la perspectiva de la función que ejercen los medios y tecnologías en el proceso compositivo. A pesar de la heterogeneidad de estilos, se hace hincapié en ciertas constantes y en sus implicaciones discursivas debido a que proponen un cambio de paradigma estético y cultural que rompe con las expectativas tradicionales de lo que se entiende por texto, poema, autor y lector. Dentro de esta línea creativa se sitúan escrituras como IP Poetry de Gustavo Romano, la biopoesía de Eduardo $\mathrm{Kac}$, las instalaciones e intervenciones poéticas de José Aburto, así como otros modos de escritura poética como la performativa o la videopoesía..

\section{PALABRAS CLAVE:}

Poesía experimental latinoamericana, ciborg, José Aburto, Gustavo Romano, tecnoescritura.

\begin{abstract}
:
This article explores different modalities of experimental writing in Latin America from the role of mediums and technologies in the compositional process. Despite the heterogeneity of styles, emphasis is placed on certain constants and their discursive implications that propose a change of aesthetic and cultural paradigm, breaking with traditional expectations of what is meant by text, poem, author and reader. Within this creative line we can include IP Poetry by Gustavo Romano, Eduardo Kac's biopoetry, installations and poetic interventions by José Aburto, as well as other styles of poetic writing such as performative and videopoetry.
\end{abstract}

\section{KEYWORDS:}

Latin American experimental poetry, cyborg, Jose Aburto, Gustavo Romano, technowriting. 
For the last three hundred years, poems have enjoyed a tangible presence as they came into being through the poet's knuckled hand. No longer.

K. Stein ${ }^{1}$

Los cuerpos son mapas de poder e identidad y los ciborgs no son una excepción. D. Haraway ${ }^{2}$

los no objetualismos no son solo nuevos géneros artísticos, sino que representan las nuevas formas de pensar la realidad desde el arte.

M. Bustamante ${ }^{3}$

Una de las tendencias más recientes de la poesía experimental es la que se enmarca en una cultura y una estética de interfaces que acentúa nuevas relaciones entre signo, cuerpo (materialidad) y escritura. Los autores que trabajan en esta línea prestan cada vez más atención a materialidades alternativas al papel, a la fusión y convergencia de medios, a la hibridación y a la intermedialidad, entre otras características. En los distintos estilos, poesía ciborg, tecno-poesía, biopoesía, videopoesía, instalaciones e intervenciones poéticas, poesía performativa, etc., los artistas suelen emplear interfaces que actúan en calidad de signos, voces, e incluso operan en función de entidades co-autoras del poema. Una interfaz, en sentido amplio, puede ser una frontera física o virtual compartida entre dos o más componentes de un sistema en el que se intercambia información. El intercambio de significantes puede ser entre software, hardware, dispositivos periféricos, voces de los lectores, etc.

Conviene indicar que uno de los rasgos de la escritura experimental es que el lenguaje alfabético deja de tener prioridad semiótica o preferencia exclusiva tanto en la composición como en la expresión y el estilo del poema. Los nuevos signos del poema proceden de lenguajes verbales, matemáticos, geométricos, etc., y constituyen los nuevos fonemas del texto y agentes sígnicos, los cuales significan de acuerdo a la interacción que el lector establezca con el texto. El proceso de organización de los signos del poema no obedece necesariamente a una matriz central, no tiene por qué haber un significado, es decir, puede ser una organización asemántica, azarosa

${ }^{1}$ Kevin Stein, Poetry's Afterlife: Verse in the Digital Age. Ann Arbor, MI: University of Michigan Press, 2010, pág.158.

${ }^{2}$ Donna Haraway, Manifiesto Ciborg. El sueño irónico de un lenguaje común para las mujeres en el circuito integrado. [1984] en https://xenero.webs.uvigo.es/profesorado/beatriz_suarez/ciborg.pdf. 1991, pág. 28.

${ }^{3}$ Maris Bustamante, «Árbol genealógico de las formas PIAS» [1998], en https://marismariamagdalena. wordpress.com/2012/09/04/arbol-genealogico-de-las-formas-pias-2/ 2012, pág.1 . 
y fragmentada. Y es dentro de esa fragmentación y diversidad de signos orgánicos e inorgánicos que el lector activa uno de los posibles sentidos del poema.

Esa combinación de signos y lenguajes crea un lenguaje integrado compuesto de lenguajes primarios que es el que el lector debe descodificar de modo no lineal. El proceso de significación en estas escrituras no se produce tanto por la presencia sintagmática de los fonemas, palabras y versos convencionales, como por el carácter aleatorio de signos de diversa naturaleza, en un conjunto que integra lenguajes no verbales. ${ }^{4}$ En este contexto, los fonemas, los objetos y las voces de la escritura experimental necesita de la interfaz de ciertas tecnologías visuales, sonoras, cibernéticas, gráficas, etc.

En estas nuevas condiciones comunicativas y creativas, el poema utiliza la remediación como agente semiótico y requiere una descodificación de signos verbales y no verbales, así como de códigos geométricos, numéricos, etc., y formatos diversos (plataformas físicas, espaciales, objetuales o virtuales). Un análisis de topografías de estilo permite reconocer y clasificar la naturaleza compositiva alterada de estas textualidades. De acuerdo a J. D. Bolter y R. Grusin (1999), los medios de representación tienen la capacidad de «remediar», es decir, de apropiar y modificar prácticas representativas de otros medios artísticos como la pintura, la literatura en papel, la fotografía, el cine, el teatro, etc. Sin embargo, no se trata de algo nuevo pues algunos géneros clásicos como la pintura o la literatura tenían ya la capacidad de hacer un tipo de remediación con técnicas ilusionistas que podían evocar o proyectar modos representacionales de otros medios.

Las poéticas experimentales suelen explotar de modo particular la remediación que funciona como un lenguaje integrado compuesto de distintos medios y tecnologías que configuran textos hipermediáticos (textos, gráficos, animación, vídeos, sonidos) en una misma pantalla o poema ofreciendo la ilusión de naturalidad. Las señales de mediación son signos que integran espacios visuales, sonoros, etc. Un aspecto de la remediación y la hipermediación es el efecto de inmediatez y espontaneidad que provoca en el lector. Es en este sentido que podemos decir que la tradición tangible, material o física, de la literatura tradicional está en crisis, es decir, en estado de transformación debido, en parte, a los nuevos procesos compositivos que requieren una mayor interacción con las tecnologías.

Existen multitud de proyectos de escritura experimental en Latinoamérica como es el caso de la escritura ciborg en la que destaca el proyecto IP Poetry del artista vi-

\footnotetext{
${ }^{4}$ En la poesía lírica actual también existen motivos recurrentes, análogos a los mencionados en la poesía tecno-experimental como la escisión, la fragmentación del ser humano, la desmembración, el proceso de metamorfosis, la otredad, la multiplicación de identidades, el doble, etc., aunque estos son motivos que se expresan exclusivamente a través del lenguaje verbal.
} 
sual argentino Gustavo Romano. En 1995 Romano creó el sitio web Fin del Mundo, una de las primeras plataformas de exhibición y difusión del net art en Iberoamérica. Otro proyecto pionero es la biopoesía del artista y crítico brasileño Eduardo Kac, para quien la década de los ochenta es el tiempo en el que la poesía se sale de manera efectiva de la página impresa y aparece en nuevos códigos y medios. La biopoesía es un proyecto polémico en el sentido que combina el uso de la biotecnología y organismos vivos como un nuevo campo para la creación verbal. Su poesía transgénica, uno de los varios proyectos de escritura biopoética, ${ }^{5}$ se basa en sintetizar el ADN con códigos inventados (artificiales) para escribir palabras y frases usando combinaciones de nucleótidos. Luego, según el autor, por medio de la mutación y pérdidas naturales y de intercambio del código de ADN surgirán nuevas frases y oraciones.

Otro proyecto de escritura poética son las instalaciones e intervenciones poéticas «Pequeñas interfaces poéticas» del artista peruano José Aburto Solezzi. El trabajo creativo de Aburto se basa en experimentar con formatos, escrituras y soportes en los que reinterpreta el quehacer poético de manera personal, pero a través del uso e intervención de las tecnologías, en un deseo de utilizar ambos hemisferios cerebrales, el intuitivo y el analítico. En su serie de «cubos» el poeta utiliza diversas interfaces como pantallas conectadas a ruedas, el sonido del lector, etc., que modulan la escritura de acuerdo a la interacción espacio-temporal del lector con el cubo.

En estas escrituras, los espacios y materialidades del poema requieren la incorporación de nuevos elementos de estudio al tiempo que confirman un nuevo paradigma cultural y estético. El vocabulario integrado del poema puede estar compuesto de dispositivos tecnológicos y externos al texto que, en el momento de la lectura o visualización del poema, adquieren valor de signo. Este es el caso de las cuatro voces robot de IP Poetry que activan con un clic una lectura posible por parte del lector. Los biopoemas de Eduardo Kac, de forma análoga, crean nuevos procesos compositivos que revolucionan no solo el paradigma tradicional que separaba las artes de las ciencias sino también la forma de concebir la escritura al generar nuevos lenguajes híbridos (artificiales y orgánicos) con fines estéticos.

Se puede afirmar que la naturaleza intermedial e hipermedial de estas escrituras y su capacidad para comunicarse a través de múltiples textos y lenguajes simultáneamente -cine, fotografía, pintura, vídeo, performance, música, etc.,-- está produciendo escrituras poéticas no lineales sin precedentes al superar los límites convencionales de escritura. Esto requiere una reconceptualización del poema, del autor, del texto y de lo que se solía entender o definir como signo.

\footnotetext{
${ }^{5}$ Otros estilos de biopoesía creados por Kac son la escritura amébica, la poesía bacterial, la escritura atómica, la escritura xenográfica, la protopoética, la nanopoética, etc.
} 
La integración de interfaces, múltiples unidades de tiempo (silencios y voces pregrabadas), la presencia de interfaces, espacios geométricos y lenguajes orgánicos e inorgánicos, materiales o virtuales en el poema exige una interacción visual diferente a la que se establecía tradicionalmente entre texto y lector/a. Los nuevos espacios de significación crean una escritura «alterada» y fluida a la vez.

Los nuevos medios y soportes de escritura en pantallas móviles y sus diversos tamaños ejercen un efecto de descentralización del formato geométrico e internacional estándar (papel A4) en el que se publicaba y leía literatura. Ahora nos hallamos ante nuevos dispositivos electrónicos que marcan diferentes pautas y expanden la lectura hacia zonas inesperadas, hipermedia, en la que un texto mínimo puede estar conectado a cientos de textos en paralelo dilatando la experiencia subjetiva de lectura.

$\mathrm{Si}$ atendemos al marco, así como también a los tipos de soporte de escritura, vemos que los espacios móviles, escultóricos móviles y geométricos adquieren un papel central en la lectura. Como indicó hace décadas, el artista uruguayo Carmelo Arden Quin «dentro del arte geométrico no hay razón para quedarse encerrado en el rectángulo o el cuadrado». ${ }^{6}$ Según la profesora Virgina Agote, «Quin propugnó el empleo de figuras geométricas triangulares, romboidales, trapezoidales, anticipándose en casi dos décadas a los cultores norteamericanos del shaped canvas». ${ }^{7}$ En la década de los 30 y 40, Quin y otros artistas plásticos de vanguardias estaban trabajando conscientemente con las posibilidades semióticas del marco. En la actualidad se están reincorporando y materializando diversos principios y conceptos articulados en las distintas vanguardias. Una diferencia es que las nuevas tecnologías intervienen en el proceso semiótico expandiendo y revolucionando las posibilidades de lo poético.

En la actualidad muchas tecnologías, al alcance de los usuarios, posibilitan que en una misma pantalla el poema manifieste una dimensión visual, sonora, verbal y espacial y de manera dinámica. El carácter hipermedial permite que unos fragmentos de texto dispuestos de manera interactiva nos lleven a otra pantalla o se metamorfoseen y activen, con la intervención del lector, más de un texto, más de una lectura y más de un medio simultáneamente. Tal es el caso del arte electrónico de Carlos Castellanos y Steven Barnes, ${ }^{8}$ en el que de modo parcialmente similar a la biopoe-

\footnotetext{
${ }^{6}$ Arden Quin (1913-2010), fundó la revista Arturo. Arte Madí. Movimiento, Abstracción, Dimensión, Invención (1946) junto con Martin e Ignacio Blazsko, Esteban Eitler, Gyula Kosize y Rhoz Rothfuss. Se trata de una revista de vanguardias dedicada a las artes abstractas. Véase el vídeo «Arden Quin. La invención lúdica», Museo provincial Franklin Rawson: https://issuu.com/museofranklinrawson/docs/ catalogo_arden_quin 3 de marzo, 2015,pág. 9.

${ }^{7}$ Arden Quin, op. cit., pág. 9.

${ }^{8}$ El proyecto artístico cibernético «Biopoiesis» explora las relaciones entre estructura, materia y autoorganización.
} 
sía de Eduardo Kac, se exploran las posibilidades interactivas y computacionales de procesos orgánicos (caldo primordial). Esta exploración permite a los autores vislumbrar nuevos diálogos entre las artes, el lenguaje cibernético y las ciencias. En estos procesos de laboratorio se estudian iteraciones a través de electrodos y se estudian las condiciones del ambiente en condiciones controladas. La información de los electrodos está cargada eléctricamente y está conectada a sensores, micrófonos, videocámaras, etc. Otro estilo de escritura poética, menos revolucionario que los anteriores, pero igualmente revelador de las nuevas condiciones del signo poético es el «Poemario ciborg. Insert coin(s)» del artista visual argentino Nacholabs, para quien «la política de los ciborgs es la lucha por el lenguaje y contra la comunicación perfecta, [...]. Se debe a eso el que la política de los ciborgs insista en el ruido y sea partidaria de la polución, regodeándose en las fusiones ilegítimas de animal con máquina». ${ }^{9}$

Las múltiples plataformas activas de las escrituras experimentales estimulan un nuevo entendimiento de lo poético que exige una revalorización del signo literario, y una nueva definición de texto, autor y poema. El signo literario se compone de fonemas y sonidos verbales y materiales, mecánicos, humanos, voces, etc. El texto no lineal, no secuencial no tiene unidad y puede componerse de múltiples textos y lecturas. En estos poemas, las máquinas, los programas de inteligencia artificial, son signos. Dejan de ser un mero instrumento externo para convertirse en voz o en coautores del poema. El poema ya no es un producto formal y temático exclusivo del autor. El poema puede incluir también espacios orgánicos (ADN) e inorgánicos, en el ámbito de la programación. La lectura se realiza en una zona intersticial de convergencias y que no ha sido suficientemente mapeada todavía, en la que intervienen lenguajes verbales y nuevos lenguajes artificiales.

En este contexto hay que recordar que la transformación de los modos de composición y producción no ha surgido de repente, sino que las intenciones programáticas se han ido gestando y articulando desde hace varias décadas. En esta época es que podemos ver materializados proyectos de escritura que antes no eran posibles, en virtud de nuevos modos creativos con las tecnologías. Asistimos a una nueva fase poética tecno-compositiva que utiliza la materialidad orgánica y la inteligencia artificial como signos de un nuevo lenguaje y que, en cierto sentido, está vinculado a la tradición de la ruptura ${ }^{10}$ que caracterizaba a las vanguardias históricas.

\footnotetext{
${ }_{9}^{9}$ Nacho (Nacholabs), «Poemario ciborg. Insert coin(s)» http://nacholabs.com.ar/poemario/ sin página y $\sin$ fecha.

${ }^{10}$ La tradición de la ruptura es un concepto que ha sido articulado por Octavio Paz en Los hijos del limo: Del Romanticismo a la Vanguardia, Barcelona, Seix Barral, 1974.
} 
Algunos de los precedentes más visibles de las escrituras experimentales latinoamericanas actuales fueron los movimientos de vanguardias de los años 20 y 30 tales como el creacionismo, el dadaísmo, el cubismo, el futurismo, el surrealismo, y los movimientos interartísticos de los años 60 y 70, el concretismo, el espacialismo, el minimalismo, el letrismo, etc., los cuales se nutrían de una tradición interdisciplinaria pictórica, musical, gestual, escénica, escultórica internacional y experimental antiinstitucional. Es el caso de Fluxus, George Maciunas, Dick Higgins, John Cage, Joseph Beuys, y otros. La articulación multiforme de las vanguardias interartísticas ha abierto el camino a una nueva conceptualización del poema y nuevas modalidades de escritura poética. El impulso de renovación de la escritura experimental en Latinoamérica ha venido también de la mano de artistas cultores (Perednik, 2016) como el poeta argentino Edgardo Antonio Vigo, el artista plástico uruguayo Carmelo Arden Quin (el movimiento Madi), los poetas concretistas brasileños, los hermanos Pignatari y el boliviano-alemán Eugem Gomringer, en los años 50, el uruguayo Julio Campal en la España de los años 60, fundador del grupo «Problemática 63» e impulsor del grupo «N.O.», etc. A esto hay que añadir los avances tecnológicos en computación que han hecho posible un proceso de convergencia entre signos, lenguajes y tecnologías, creando nuevas textualidades de carácter público, colaborativo, tecno-creativo, intermedial, transgénero y objetual.

Un breve recorrido por las escrituras experimentales latinoamericanas actuales muestra que los autores son receptivos nuevamente a la figura del artista total, típica del cinquecento renacentista, en esta era posthumanista. ${ }^{11}$ La creatividad, sin embargo, está teñida de desafíos. Las tecnologías son un arma de doble filo. Algunas técnicas muy usadas en el intento de renovación y personalización de la escritura poética son el apropiacionismo, la recreación, la remediación y la fusión de aspectos formales o estilísticos que proceden de distintas vanguardias históricas. Un caso es la estética modular practicada por José Aburto que evoca el arte escultórico de Mitzi Cunliffe 1950-1960, y algunas obras de Norman Carlberg, de los años 1970. Esta escritura modular también responde a inquietudes culturales de carácter tecno-industrial y postindustrial. Su naturaleza dinámica, espacial y arquitectónica se basa en la combinación de configuraciones materiales independientes para crear una nueva sintaxis. Estas escrituras proyectan varias dimensiones textuales, materiales y virtuales en un mismo poema objetual y virtual.

\footnotetext{
${ }^{11}$ En el Renacimiento la figura del artista total era un modelo por seguir, lo cual contrasta con la posterior separación de las artes y las ciencias. Esa época produjo artistas de la talla de Leonardo Da Vinci, Miguel Ángel o Rafael Sanzio que dominaban varias disciplinas a la vez: orfebrería, escultura, arquitectura, pintura con el uso de la perspectiva y las técnicas de difuminado, pero también matemáticas, geometría, filosofía humanista, etc.
} 
La biopoesía emplea la remediación como estrategia que expande los límites conocidos entre procesos orgánicos e inorgánicos. Las escrituras experimentales también pueden utilizar estas técnicas para responder a ámbitos geopolíticos de represión y carencia como es el caso de la poesía visual en Cuba, que durante décadas ha cultivado distintos grados de radicalización formal, hermetismo, fusión, apropiación y materialización con fines ideoestéticos.

Otro aspecto a tener en cuenta es que, debido a la constante proliferación de estilos, es difícil hablar de una única tendencia homogénea que legitime las nuevas escrituras, a pesar de que hay una abundante literatura crítica y taxonómica al respecto (Higgins 1966; Kress 1998; Bolter, 1999; Clüver 2001; Glazier 2002; Hayles 2002; Prohm 2006; Stein 2010; Funkhouser 2012; Zazil 2014; Ledesma 2016). La falta de consenso por parte de la crítica con respecto al estatus y definición de estos estilos tan heterogéneos evidencia el estado intermedio y fluctuante en el que se hallan estas escrituras. Como indica Kevin Stein (2010), esto puede ser debido a que las nuevas escrituras mediáticas existen en un dominio en el que no hay todavía una taxonomía suficiente, estable o segura, o según G. Kress, tenemos un nuevo paisaje y se necesita una nueva teoría de significación «the landscape is being remade and our need for a new theory of meaning is utterly significant». ${ }^{12} \mathrm{Si}$ a esto le añadimos la afirmación de Dick Higgins cuando identificaba a la «mejor poesía» del siglo XX con la que se producía fuera de los géneros establecidos «Much of the best work being produced today seems to fall between media» ${ }^{13}$, urge un nuevo acercamiento que legitime estas escrituras desde una multiplicidad de ángulos divergentes.

El modo compositivo híbrido en el que incurren nuevos acoplamientos y signos; ciborg, biopoesía, etc., favorece la coparticipación y la copresencia en el poema de lenguajes primarios, integrados y codificados. La tecnología permite la presencia de texto, sonido, imagen, animación y vídeo en una plataforma compositiva única (A. Prohm, 2008). La integración de medios, formatos y lenguajes en el mismo texto es una propiedad semiótica de la escritura experimental que permite la presencia de elementos orgánicos e inorgánicos, virtuales, sonoros, etc., y en la que se proyectan de modo inseparable varias formas y lenguajes. La superposición de textos, imágenes y sonidos en alineamientos diversos en una misma plataforma virtual puede

\footnotetext{
${ }^{12} \mathrm{G}$. Kress, «Visual and verbal modes of representation in electronically mediated communication: The potentials of new forms of text.» en I. Snyder (Ed.) Page to screen: Taking literacy into the electronic era. London: Routledge, 1998, pág. 59.

${ }^{13}$ D. Higgins, «Synesthesia and Intersenses: Intermedia» en Something Else Newsletter 1, No. 1, 1965, pág.1. Y en Horizons, the Poetics and Theory of the Intermedia. Carbondale, IL: Southern Illinois Univ. Press, 1984.
} 
ofrecer la ilusión de una percepción completa del texto añadiendo una dimensión semiótica adicional al texto.

Otro aspecto vinculado a los nuevos modos de producción es que las nuevas tecnologías además de transformar los procesos compositivos también requieren nuevos modos de conservación de estas obras. En la época en la que predominaba la cultura y la literatura escrita, no se necesitaban requisitos especiales para su conservación. Las nuevas escrituras tecno-poéticas evidencian un momento histórico muy relevante, pues las escrituras virtuales se guardan en zonas de ceros y unos.

El proceso de conservación de la escritura es otra forma de manifestación de la alteración de las artes y de nuevos requisitos para una receptividad apropiada. Como afirma Kevin Stein:

The widespread use of computer and digital media is transforming not only how poets compose their work but also how they preserve it, or fail to. Denizens of the digital age, we inhabit a historical moment where much exists only as codes of zeroes and ones. It stands to reason current literary manuscripts will likely be affected by technological innovation in ways we can't yet imagine, as technology - like rust-never sleeps. Its forward movement continually alters the terrain of art's creation and reception. ${ }^{14}$

Una característica relevante del uso de los medios en esta escritura es que favorecen una estética transversal al tiempo que facilitan la proyección de discursos de resistencia cultural y estética que cuestionan, problematizan o expanden conceptos convencionales en torno a la identidad, al género, la subjetividad, la nación, etc. Este doble proceso, crítico y creativo, se puede analizar desde varios ángulos. Y, si bien, los poetas experimentales cultivan formas y estilos con intenciones muy diferentes, hay zonas intersticiales comunes que se pueden analizar desde una perspectiva ideológica de resistencia. Independientemente de los rasgos formales y estructurales propios de cada autor y época, la poesía experimental del siglo XX y lo que va del XXI, manifiesta una tendencia ideoestética (ideológica y estilística) colaborativa, de resistencia cultural a patrones dogmáticos en arte y pensamiento, y está fraguando una forma diferente de repensar la cultura, el arte y la identidad.

Algunos poetas latinoamericanos que han iniciado o desarrollado escrituras poéticas no lineales en México y Cuba son José Juan Tablada (México), Octavio Paz (México), Jack Seligson (México), Felipe Ehrenberg (México), Guillermo Villegas (México), Guillermo Santamarina (México), Armando Sarignana (México), Yanni Pecannis (México), Oscar David López (México), Maris Bustamante (México), Pablo Espinosa (México), Carlos Pineda, (México), Pedro Marqués de Armas (Cuba),

\footnotetext{
${ }^{14}$ Kevin Stein, op .cit., 2010, pág.158.
} 
Carlos A. Aguilera (Cuba), Rolando Sánchez Mejía (Cuba), Francis Sánchez (Cuba), Rafael Almanza (Cuba), Carlos M. Luis (Cuba), Severo Sarduy (Cuba), Samuel Feijóo (Cuba), Carlota Caulfield (Cuba). Esta es una lista parcial de autores latinoamericanos y, obviamente, para ser representativa debe incluir a poetas de todos los países latinoamericanos.

En México, un país con una larga trayectoria poética experimental y, en muchos casos, al margen de la industria editorial y cultural, se ha practicado una escritura experimental que responde a discursos ideoestéticos de resistencia que van desde los estilos cercanos a la poesía verbal hasta el arte escenográfico. La crítica literaria comienza a hacerse eco de estas escrituras híbridas y desde principios del siglo XXI destacan publicaciones como el número 23 de la revista Alforja XXIII y el libro La poesía visual en México (2011), editado y coordinado por Samuel Gordon. También, como constata Gabriel Hernández Espinosa, en 2013 se publicó la antología Poesía visual mexicana. La palabra transfigurada, coordinada por Carlos Pineda.

Algunas figuras pioneras son José Juan Tablada (1871-1945), introductor del haiku, los tanka y la poesía ideográfica en Li Po y otros poemas (1920). También cabe destacar el movimiento estridentista y su fundador Manuel Maples Arce con Comprimido Estridentista (Manifiesto) en Actual N. 1 (1921). Dentro del estridentismo destacan Arqueles Vela, Germán List Arzubide, Germán Cueto, Fermín Revueltas, Ramón Alva de la Canal, Luis Quintanilla del Valle y Leopoldo Méndez. Este movimiento vanguardista, que duró unos seis años (1921-1927) introdujo, entre otros rasgos, la plasticidad en poesía y una rebelión a las tradiciones literarias con un programa de intenciones muy explícito.

En la década de los 60 en poesía visual y experimental surgen los primeros poemas iconográficos y mandalas. Una figura clave fue Octavio Paz con Blanco (1966), Discos visuales (1968), Topoemas (1968) y Vuelta (1969-1975), en el que el ideario poético se concibe como objeto de creación incesante en un vasto sistema de signos en rotación. Paz ha trabajado la poesía espacial e ideogramática, por oposición a la poesía temporal o discursiva, secuencial convencional. En este tipo de poesía los signos del poema incluyen varios sistemas de comunicación, verbal y no verbal.

Conviene mencionar que, en Blanco (1966), Octavio Paz enfatiza la relatividad de las categorías espacio-tiempo:

El espacio fluye, engendra un texto, lo disipa - transcurre como si fuese tiempo. A esta disposición de orden temporal y que es la forma que adopta el curso del poema: su discurso, corresponde otra, espacial: las distintas partes que lo componen están distribuidas como las religiones, los colores, los símbolos y las figuras de un mandala... (1966: 481) ${ }^{15}$

\footnotetext{
${ }^{15}$ Texto de O. Paz, recogido en Poemas (1935-1975), Seix Barral, 1979.
} 
Otros artistas experimentales y conceptuales mexicanos son Matías Goeritz, Jack Seligson, Felipe Ehrenberg (1943) y Ulises Carrión (1941-1989). Carrión fue un autor polémico que rompió muchos moldes literarios convencionales. Su obra se concebía como una serie de textos o antitextos y su escritura como una desescritura. En palabras de Marcial López:

Textos tachados, borrados, corridos, desdoblados; textos que lloran lágrimas de tinta, textos borrosos como si los estuviera mirando un miope, textos separados por cesuras, encerrados en tubos de colores, juegos tipográficos en la página en blanco: XJR. PZS. BTQ. ${ }^{16}$

En la década de los 70 se produce un incremento de actividades poético experimentales a través de instalaciones, poesía neográfica, arte público, performances, la música del cuerpo de Guillermo Villegas y Consuelo Deschamps, y «Cosafono» y la partitura visual «Andante». También surgió el proyecto «Atelén» de Laura Elenes con elementos plásticos, sonoros y computerizados. En los años 80 destacan entre otros, Pablo Espinosa y su libro de poesía semiótica «El semiófago». En esta época, Mónica Mayer y Maris Bustamante fundaron el grupo de arte feminista «Polvo de Gallina Negra» en 1983. Fue el primer grupo de esta naturaleza en México. En las décadas de los 70 y 80 las formas experimentales más comunes en México fueron las formas llamadas PIAS, (Performance, Instalaciones y Ambientaciones) por Maris Bustamante, artista independiente, pionera de las artes visuales y no objetuales, escenógrafa, museógrafa, realizadora de arte objeto, arte correo y performance. En sus palabras:

...los no objetualismos no son solo nuevos géneros artísticos, sino que representan las nuevas formas de pensar la realidad desde el arte. Como son desarrolladas por artistas radicales, para muchos impíos, las he denominado como las Formas PIAS, término que parecer haber sido bastante taquillero. ${ }^{17}$

La trayectoria interdisciplinaria de Bustamante es digna de mención. Bustamante perteneció a No Grupo (1979-1985), junto a Melquíades Herrera y Rubén Valencia (creador del concepto). Este fue el primer colectivo de arte no objetual en México.

\footnotetext{
${ }^{16}$ David Marcial López, «Los libros que intentaron asesinar a la literatura», en El País. 25 de febrero, 2017, pág. 1.

${ }^{17}$ M. Bustamante, «Árbol genealógico de las formas PIAS» Generación. 1998, pág. 1. Véase también el artículo de Bustamante: «Formas Pías: Cartografías incompletas en la obra de Juan Acha» en Post Notes on Modern and Contemporary Art around the Globe, 28 Sept. 2017: https://post.at.moma.org/ content_items/1042-formas-pias-cartografias-incompletas-en-la-obra-de-juan-acha
} 
Después participó en el primer grupo de arte feminista, junto con Mónica Máyer, «Polvo de Gallina Negra», remedo contra el mal de ojo, que servía de autoescarnio/ defensa «porque era duro ser mujer, pero si además de tener esta condición se es artista y feminista, era peor, así que decidimos protegernos con el nombre». ${ }^{18}$

Una forma de resistencia cultural, de acuerdo a Bustamante, es la propia condición nacional y étnica del pueblo mexicano: «en México, nuestra dualidad mesoamericana, centrada en la Coatlicue, nos da la posibilidad de estar en el pensamiento europeo occidental, pero nunca implementado con total éxito; hay una resistencia, sobre todo, en lo que las culturas pragmáticas nos reclaman». Otras formas de resistencia cultural y artística vienen apoyadas por el empleo de nuevos soportes o del mismo cuerpo de la artista, usado como sujeto y objeto con el que se cuestiona, experimenta y transforma.

La llamada generación de Los Grupos en los setenta (grupos de artistas fuera de las academias y del arte oficial con mujeres poetas, fotógrafas, escultoras, etc.,) buscaba en sus acciones la libertad de expresión, la lucha por la democracia, la igualdad de derechos, etc.

Algunos de los acontecimientos asociados a formas radicales de poesía emergen con motivo de la matanza en Tlatelolco (1968), el programa de las fronteras entre México y EE.UU. «North American Free Trade Agreement» (NAFTA, 1991, hoy T-MEC), el movimiento del ejército zapatista (1994), los cárteles de las drogas, etc.

En los años 90 proliferan en México obras de carácter intermedio, además de las instalaciones y performances que ya eran una práctica común de décadas anteriores. En esta época destacan figuras de la talla de Guillermo Santamarina, Armando Sarignana, Yanni Pecannis, (libros objeto), Gabriel Macotela, mail art (CRAG, Aquí, Colectivo-3), Felipe Ehrenberg, Marcos Kurticz (+1995), Maris Bustamante, Víctor Muñoz with X'Teresa Centro de Arte Alternativo, Óscar David López, Farmacopedia y Mapping (2015).

La poesía experimental de Cuba también merece especial atención dentro del contexto latinoamericano porque la trayectoria poético experimental de dentro de la isla no presenta sincronicidad con el resto de los países latinoamericanos. También destacan poetas experimentales de la diáspora como Severo Sarduy con Flamenco (1970), Big Bang (1973), Mood indigo (1970), radicado en París y la obra de carácter visual y surrealista de Carlos M. Luis radicado en EE.UU. Más recientemente resaltan figuras como Carlos A. Aguilera, Rogelio Saunders, Rolando Sánchez Mejías, Francis Sánchez y otros poetas radicados en España y otros países europeos. La

\footnotetext{
${ }^{18} \mathrm{~J}$. Caballero, «Los artistas deben encontrarle pistas a la realidad: Maris Bustamante» en La Jornada. 3 de noviembre de 2005, pág.1. https://www.jornada.com.mx/2005/11/03/index.php?section=especta culos\&article $=$ a $14 n 1$ esp
} 
poesía de dentro de la isla presenta una evolución diferente. La crítica subraya la ausencia de una verdadera poesía de vanguardias en Cuba. Algunos factores son la falta de medios que ha abocado a la poesía cubana de dentro de la isla a utilizar los modos tradicionales a su alcance como la escritura en papel, puesto que el acceso a la tecnología y al internet tiene un uso muy limitado. No es hasta las últimas décadas que algunos poetas dentro de Cuba comienzan a hacer uso experimental de la escritura poética. Otros poetas representativos de Cuba son Samuel Feijóo (caligramas), Guillermo Cabrera Infante (poesía visual, caligramas), Francisco Garzón Céspedes, Desde los órganos de la puntería (1971), Rafael Almanza, la poesía del grupo Diáspora (1993), Octavio Armand, Yornel Martínez, Yeni Casanueva (Proyecto Procesual), Alejandro González, etc.

Argentina, al igual que México, tiene una larga y rica trayectoria poética. Algunos miembros del movimiento Paralengua son Fabio Doctorovich, César Espinosa, Carlos Estévez, J.S. Perednik y Alonso Barros Peña. En este libro Jait reconoce la tradición inaugurada en la década del veinte con Oliverio Girondo, Xul Solar y Jorge Luis Borges, en la revista Martín Fierro y se continúa con Macedonio Fernández, el arte concreto, Madí, Poesía Buenos Aires, y E. A. Vigo, como antecedente inmediato. Factores de contexto incluyen la última dictadura militar argentina, el alfonsinismo y el menemismo.

Merece destacar la obra de Carlos Ginzburg, la poesía fonética de Luis Pazos, Jorge de Luján Gutiérrez, Edgardo A. de Vigo, Juan Carlos Romero, Fernando García Delgado, Claudia del Río, Lilian Escobar, Ana María Uribe, Hilda Paz, Susana Romero Sued, Jorge Macchi, Susana Fernández Sachao, Belén Gache, Ariel Gangi, Fernando Strano, Fabio Doctorovich, etc. Al igual que en España y en México, en Argentina existe una producción importante generada por movimientos y grupos poéticos tales como el «Movimiento Diagonal Cero» (1966-1969) que estaba integrado por Edgardo Antonio Vigo, Luis Pazos, Jorge de Luján Gutiérrez y Omar Gancedo, el grupo «Escombros. Artistas de lo que queda» que nace en 1988 y reúne poetas como Angélica Converti, Raúl García Luna, Luis Pazos, Óscar Plasencia y Héctor Puppo, Juan Carlos Romero, Horacio D’Alessandro, David Edward. También destaca el proyecto «Vórtice Argentina» iniciado en 1996 por Fernando García Delgado con la participación de cientos de artistas en géneros tan diversos como la poesía visual, sonora, experimental, el arte correo, el libro de artista, acciones y performances.

Estos son artistas polifacéticos que trabajan en más de un género y lenguaje artístico, ya sea pintura, diseño gráfico, narrativa, poesía verbal, crítica literaria, teatro, música, cine, etc. Independientemente del país de origen, estos poetas exploran nuevas formas de comunicación transdisciplinaria y hay un énfasis por la escritura 
visual, performativa y, en menor medida, por la escritura ciborg. Un rasgo común de todas estas escrituras es que se explota la interdependencia entre sujeto y objeto ( $\mathrm{Ni}$ colescu, 2006, 2008c), se tiende a conceptualizar la cuestión del género y escritura y se crean formas híbridas de discurso compuestas por múltiples lenguajes artísticos y soportes.

El análisis de los diversos estilos experimentales desafía taxonomías tradicionales y nos invita a reflexionar en torno a tipologías, topologías, técnicas, así como el papel del lector y del autor en el proceso de lectura:

- Tipología. Identificación y definición de estilos; algunos estilos son determinados por los poetas mismos y en algunos casos coinciden con la nomenclatura dada por la crítica. En otros casos son géneros en formación y pueden ser clasificados de acuerdo a varios criterios.

- Topología. Propiedades materiales, físicas, virtuales, gráficas y geométricas, relaciones espaciales, dimensionalidad, etc.

- Técnicas. Impresión digital, collage, ilustraciones, materialidad de los signos y tipografía (tamaños, fuente, altura, textura, etc.), puntuación, presentación visual y espacial, sonora, imágenes compuestas, técnicas de reproducción.

- Intermediación. Incorporación e interacción de varios medios y generadores multimedia, algoritmos, operaciones meta-representativas y sintaxis autorreferencial.

- El papel del lector. La lectura como un acto público y privado. La lectura como proceso interactivo y como acto de performance. La lectura como proceso cognitivo, perceptivo y como experiencia holística.

- Conceptos de autoría. Autores combinados (humanos-máquinas), autores individuales, colectivos, autores anónimos, seudónimos colectivos.

El carácter transdisciplinario e híbrido de estas poéticas no lineales puede ser analizado desde varios acercamientos teóricos como la semiótica verbal y visual (F. Saussure, 1966; R. Barthes, 1968; M. Riffaterre, 1978; U. Eco, 1986; Hawkes 1977; O'Toole, 1994); la multimodalidad (Dick Higgins, 1965; O'Halloran, 2008); la materialidad del signo poético (Lakoff, 2012); la intermedialidad (Portela, 2013) o la poética como proceso (Malabou, 2007). Estos acercamientos ofrecen diferentes enfoques de investigación y ayudan a interpretar y conceptualizar el fenómeno de la convergencia entre distintos medios, modalidades y géneros, así como a investigar sus efectos. La intersemiótica es un marco útil dentro del contexto transdisciplinario que, sin excluir la validez de otros modelos de análisis, nos permite hacer análisis sistematizados de estas formas complejas de escritura y entender mejor los distintos lenguajes integrados y su dinámica. 
Una condición plural presente en la videopoesía, la tecnopoesía, la ciberpoesía, las acciones poéticas, la poesía performativa, la poesía combinatoria, la poesía permutacional, la poesía visual, objetual, gráfica, tipográfica, etc., es la no secuencialidad, la transdisciplinariedad y la multiplicidad de lenguajes. Es por ello que frente al panorama poético tradicional las poéticas experimentales presentan un status ambiguo e indefinido con respecto al canon literario y artístico. El proceso de borrar las tradicionales distinciones entre arte y literatura, así como entre ciencia, tecnología y arte, ayuda a crear una nueva conciencia y una nueva conceptualización de los límites entre arte y escritura y, como afirma Alan Prohm (2008), hace que lo verbal opere como visual, y lo visual se convierta en un lenguaje en sí mismo, por ejemplo, condicionando al lector a usar simultáneamente ambos hemisferios del cerebro: el hemisferio izquierdo que controla el lenguaje, el pensamiento lógico, la escritura, las matemáticas y el hemisferio derecho, más holístico, intuitivo, atemporal, y simbólico.

Como se ha mencionado anteriormente, se trata de prácticas híbridas textuales y no textuales, compuestas por lenguajes convencionales y con tecnologías tradicionales y modernas. Son escrituras que investigan una variedad de temas compositivos y metapoéticos (sujeto, poema, objeto, escritura, texto, autor, lector, etc.) y que involucran discursos científicos yendo más allá de los territorios poéticos tradicionales y desafiando los sistemas de significación y representación convencional. Estos estilos se sitúan en la intersección de las artes, las ciencias y la tecnología configurando nuevas relaciones lógicas y creativas entre lo percibido como realidad física, material y simbólica y lo no conocido. Estas nuevas formas y soportes de escrituras presentan un paradigma ideoestético que puede cambiar de modo radical lo que se conoce como poesía tanto oral como escrita.

\section{Bibliografía}

Aburto, José, «Pequeñas interfaces poéticas» http://entalpia.pe/entalpia/expos/ pip/index.htm

- -. «Small poetic interfaces. The end of click»ELO: The end $(s)$ of electronic literature, 2015. Web. 11 de enero de 2019. http://aco.booktype.pro/elo-2015-theends-of-electronic-literature/jose-aburto-small-poetic-interfaces-the-end-of-click/

Ajewsky, Irina O., «Intermediality, Intertextuality, and Remediation: A Literary Perspective on Intermediality». Intermédialités, 6, 2005, 43-64. Web. 11 abril de 2018.http://cri.histart.umontreal.ca/cri/fr/intermedialites/p6/pdfs/p6_rajewsky_text. pdf 
Bolter, Jay David y Richard Grusin, Remediation. Understanding New Media, Cambridge, Massachusetts, London, MIT Press, 2000 [1999].

Bustamante, Maris. «Árbol genealógico de las formas PIAS» [1998], 2012. Web. 2 de octubre de 2018. https://marismariamagdalena.wordpress.com/2012/09/04/arbol-genealogico-de-las-formas-pias-2/

- - , «Formas Pías: Cartografías incompletas en la obra de Juan Acha» Post Notes on Modern and Contemporary Art around the Globe, 28 Sept. 2017. Web. 2 de diciembre de 2018. https://post.at.moma.org/content_items/1042-formas-piascartografias-incompletas-en-la-obra-de-juan-acha

Caballero, Jorge, «Los artistas deben encontrarle pistas a la realidad: Maris Bustamante» La Jornada. 3 de noviembre de 2005. Web. 10 octubre de 2018. https://www. jornada.com.mx/2005/11/03/index.php?section=espectaculos\&article=a14n1esp

Castellanos, Carlos y Steven J. Barnes. «Biopoiesis. Cibernetics, Art and Ambiguity». Leonardo Electronic Almanac 22, no. 2. Cambridge, MA: LEA / MIT Press, 2017. Web. 7 de enero de 2019. https://contemporaryarts.mit.edu/pub/biopoiesis

Clüver, Claus, «Inter Textus / Inter Artes / Inter Media, » Aletria. Revista de estudos de literatura, 14, 2006, 2-32. Web. 10 de agosto de 2018.

Funkhouser, C. T., New Directions in Digital Poetry. Continuum, 2012.

Haraway, Donna. Manifiesto Ciborg. El sueño irónico de un lenguaje común para las mujeres en el circuito integrado. (1984). Traducción de Manuel Talens con pequeños cambios de David de Ugarte. Web. 11 de febrero de 2019. https://xenero. webs.uvigo.es/profesorado/beatriz_suarez/ciborg.pdf

Hernández Espinosa, G., «Poesía visual mexicana. La palabra transfigurada. Compilador: Carlos Pineda», Ancila. Crítica de la Poesía Mexicana Contemporánea, 2013. https://revistaanciladotorg.wordpress.com/2015/01/16/poesia-visualmexicana-la-palabra-transfigurada/

Higgins, Dick, «Synesthesia and Intersenses: Intermedia». Something Else Newsletter 1. 1.1965 reprinted in Horizons. The Poetics and Theory of the Intermedia. Carbondale, Edvardsville: Southern Illinois University Press, 1984.

Jait, Alelí, Poesía experimental argentina y políticas de la lengua. XUL. Signo viejo y nuevo. Paralengua. La otra poesía, Ediciones Postypographika, 2017.

Kac, Eduardo, «Biopoesía». Alea. Estudos Neolatinos, Vol. 10. 2, July-Dec., 2008, 327-333. Web. 3 de enero de 2017. http://www.ekac.org/biopoesia.br.html

Kress, G., «Visual and verbal modes of representation in electronically mediated communication: The potentials of new forms of text. » In I. Snyder (Ed.) Page to screen: Taking literacy into the electronic era. London: Routledge, 1998, 53-79. 
López, David M., «Los libros que intentaron asesinar a la literatura», El País. 25 de febrero, 2017. Web 3 marzo de 2019. https:/elpais.com/cultura/2017/02/22/ actualidad/1487797892_194565.html

McGregor, Sue L. T. «The Nicolescuian and Zurich Approaches to Transdisciplinarity» en Integral Leadership Review. June, 2015. Web 4 de noviembre de 2018. http://integralleadershipreview.com/13135-616-the-nicolescuian-and-zurichapproaches-to-transdisciplinarity/

Nacho, «Nacholabs. Poemario ciborg». Web. 3 de enero de 2019. http://nacholabs.com.ar/poemario/

Nicolescu B. Transdisciplinary and Complexity: Levels of Reality as a Source of Indeterminacy. Determinismo e Complessita. Armando Editore, Roma, 2000, 127142.

Paz, Octavio, Poemas (1935-1975). Barcelona, Seix Barral, 1979.

Perednik, Jorge, «En el cruce poético de las artes» Página 12. 4 de Oct. 2016. Web 3 de enero de 2019. https://www.pagina12.com.ar/diario/suplementos/espectaculos/6-40192-2016-10-04.html

Prohm, Alan, «VISUAL POETRY: Artists' Writing in a Para-literary» Age. Avain 1, 2008 [2006]. Web 2 de noviembre de 2018. https://alanprohm.files.wordpress. com/2013/08/visual-poetry-artists-writing-prohm.pdf

Quin, Carmelo Arden, «Arden Quin. La invención lúdica», Museo provincial Franklin Rawson. 3 de marzo, 2015. Web. 3 de febrero de 2018. https://issuu.com/ museofranklinrawson/docs/catalogo_arden_quin

_ - «MADI. Carmelo Arden Quin. (En)» 25 June 2016. Web 10 de febrero de 2019. https://vimeo.com/172232869

Romano, Gustavo, «IP Poetry». http://ip-poetry.findelmundo.com.ar/index-en. html

- -, «Fin del mundo». http://findelmundo.com.ar/intro21.htm

Stein, Kevin. Poetry's Afterlife: Verse in the Digital Age. Ann Arbor, MI: University of Michigan Press, 2010.

VVAA., The Routledge Companion to Experimental Literature describes Experimental Literature as «irreducible diverse». (Eds.) Joe Bray, Alison Gibbons and Brian McHale, 2012. 